\title{
CATS: continuous turbulence characterization station for both optical link and astronomical support
}

Christophe Giordano, A. Ziad, E. Aristidi, J. Chabé, Y. Fanteï-Caujolle, et al.

Christophe Giordano, A. Ziad, E. Aristidi, J. Chabé, Y. Fanteï-Caujolle, C. Renaud, A. Rafalimanana, "CATS: continuous turbulence characterization station for both optical link and astronomical support," Proc. SPIE 11852, International Conference on Space Optics - ICSO 2020, 118522D (11 June 2021); doi: 10.1117/12.2599373

Event: International Conference on Space Optics - ICSO 2021, 2021, Online Only 


\section{International Conference on Space Optics-ICSO 2020}

Virtual Conference

30 March-2 April 2021

Edited by Bruno Cugny, Zoran Sodnik, and Nikos Karafolas
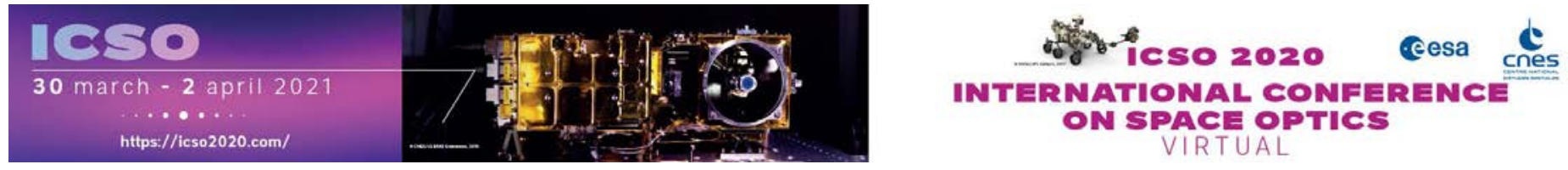

\section{CATS: continuous turbulence characterization station for both optical link and astronomical support}

\section{Cesa isoporecestings denes}




\title{
CATS: continuous turbulence characterization station for both optical link and astronomical support.
}

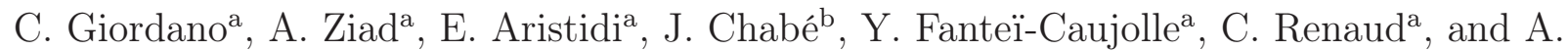 \\ Rafalimanana $^{\mathrm{a}}$ \\ a'Laboratoire J.L. Lagrange, OCA, UCA, CNRS, UMR 7293, Parc Valrose 06108 Nice Cedex 2, \\ France \\ bUniversité Côte d'Azur, OCA, CNRS, IRD, Géoazur, 2130 route de l'Observatoire, 06460 \\ Caussols, France
}

\begin{abstract}
The optical turbulence measurement and characterization has become an essential information for optical link (telecommunication, telemetry, time transfert, ...) and for high-angular resolution imagining in astronomy. It has an impact on the quality, on the bit error rate of optical communication signals and it decreases the resolution of astronomical images. The J.L. Lagrange Laboratory of the Observatoire de la Côte d'Azur has a long and recognized expertise in atmospheric optics and turbulence for astronomical purposes. We have developed recently a new generation of autonomous instruments for daytime and nighttime atmospheric optical turbulence measurement. In 2015, a complete instrumental platform, the Calern Atmospheric Turbulence Station (CATS) has been installed at the Calern observatory. CATS is an automatic station equipped with a set of complementary instruments using original techniques for monitoring optical turbulence from the first meters above the ground up to the top of the atmosphere including the dome seeing. The station is based on four instruments. PML measures continuously the vertical profiles of the refractive index structure constant $C_{n}^{2}$ with a high vertical resolution ( 100m at ground level). GDIMM monitors the wavefront coherence parameters (seeing, isoplanatic angle, coherence time, scintillation, wavefront coherence outer scale). A weather station provides the ground meteorological conditions (pressure, temperature, relative humidity, wind speed and direction). And the nighttime cloud fraction is given by an all-sky camera. Another instrument called INTENSE (INdoor TurbulENce Sensor) is occasionally associated with CATS station to measure the seeing inside the dome of the $1.5 \mathrm{~m} \mathrm{MeO}$ telescope to evaluate its contribution to the whole turbulence. A new tool has been integrated to CATS station consisting in a forecasting model using the Weather Research and Forecasting (WRF) system coupled to a turbulence model to predict daytime and nighttime meteorological and optical turbulence conditions for the next 48 h.
\end{abstract}

Keywords: Turbulence - Atmospheric effects - Instrumentation - Forecasting - Free space optical link

\section{INTRODUCTION}

Since decades the astronomical community is aware of the importance of the characterization of the atmosphere above observational site to optimize the location of instruments. In fact, atmospheric turbulence shakes the atmospheric layers of different refractive index. This phenomenon disturbs the light propagation through the atmosphere resulting in deformations and fluctuations of images acquired with telescopes.

More recently, with the development of the free space optical links, it has become apparent that turbulence also has a strong impact on signal quality, bit error rate and link budget.

For both astronomical and free space optical links, the adaptative optics is able to compensate part of the turbulence degradation. However, the dimensioning, conception and use depends on the turbulence characterization.

E-mail: cgiordano@oca.eu 
Regarding, all these points, it is clear that having an instrumentation able to measure $24 \mathrm{~h}$ a day the optical turbulence conditions is of a real interest for both astronomical and optical communications communities.

In this goal, since 2015, the Observatoire de la Côte d'Azur (OCA) has built and installed a new generation station for atmospheric turbulence characterization on the Calern Observatory. The Calern Atmospheric Turbulence Station ${ }^{1-3}$ (CATS) came out from a long and recognized expertise of the OCA/Lagrange Laboratory (OCA) in Atmospheric Optics. Indeed this laboratory played an important role in selection of the major astronomical sites over the world: GranTeCan (Canary Islands), Very Large Telescope (Chile), Southern Gemini (Chile), Keck, Northern Gemini \& Subaru (Hawaii, USA). More recently, the Lagrange laboratory was involved in the European Extremely Large Telescope (E-ELT) and the Thirty Meter Telescope (TMT) site selections. Moreover, our team was also in charge of the qualification of the site of Dome C in Antarctica whose potential in Astronomy is considerable. This later was really challenging because of the peculiar conditions of this site.

The CATS station benefits of a set of a new generation of autonomous instruments allowing the measurements of optical turbulence during both daytime and nighttime. It is a support of other project on the Calern Observatory, mainly to improve the link budget of Laser Telemetry from $\mathrm{MeO}$ station and generally free space optical links. CATS is also supporting projects on MéO (Métrologie Optique) station and C2PU (Centre Pédagogique Planète Univers) telescopes to test and validate new concepts and components in order to overcome the current limitations of existing Adaptive Optics (AO) systems. The idea is to offer to AO community a fully operational on-sky test platform. The ultimate goal being the optimization of the scientific returns of the AO assisted instrumentations.

To go further, we have recently added into the CATS station a predictive model ${ }^{4-7}$ allowing to forecast $48 \mathrm{~h}$ in advance the atmospheric and optical conditions above the Calern Observatory. This prediction tool will help, observers to plan their activities. This tool, fully automatic, will also be useful for the free space optical links because it will bring informations about the availability of ground stations dedicated to optical signals reception.

\section{THE CALERN ATMOSPHERIC TURBULENCE STATION: CATS}

The CATS station ${ }^{1-3}$ (see figure 1) is a fully autonomous station working without human needs. It is composed of a set of complementary instruments allowing the measurements of both optical and meteorological parameters:

- A weather station measures the ground parameters such as the temperature, the relative humidity or the wind speed and direction, and gives informations for the aperture of the domes.

- An all-sky camera ${ }^{2,3}$ to measure the cloud cover, and command, with the weather station, the aperture of the domes.

- A Generalized DIMM (G-DIMM) ${ }^{8-10}$ (figure 1, left) measures the nighttime integrated optical parameters such as the seeing, the isoplanatic angle and the coherence time.

- A Profiler of Moon Limb (PML) ${ }^{1-14}$ (figure 1, right) measures during daytime (on the sun limb) and nighttime (on the moon limb) the vertical profile of the $C_{n}^{2}$ with a high resolution $(\Delta h=100 \mathrm{~m}$ near the ground) and the integrated parameters (seeing, isoplanatic angle, wavefront coherence outer scale, scintillation, and, in the future, the coherence time)

- An INdoor TurbulENce SEnsor ${ }^{15,16}$ (INTENSE) which is used to estimate the turbulence inside the MéO station dome. This indoor turbulence can have a significant contribution to the degradation of the optical resolution of the telescope and optical links.

The main advantage of this station is that it acquires measurements during daytime and nighttime in an automatic way thanks to the weather station and the all-sky camera which control and allow the beginning of observations in function of the meteorological conditions. Therefore, since 2015 CATS station has acquired a large database which has been used for many studies, and which will be used for ongoing and future works in both astronomy and optical telecommunications fields. 


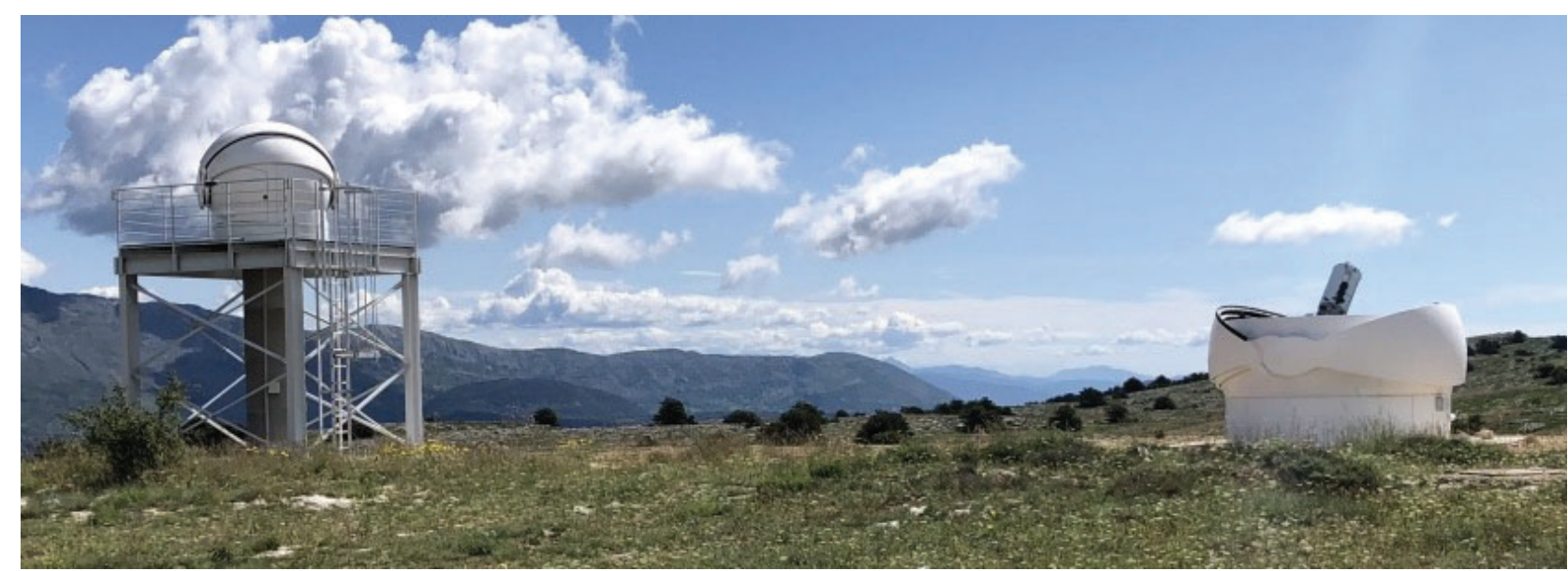

Figure 1. CATS station installed on the Calern Observatory. The left instrument is the G-DIMM, and the right one is the PML.

\subsection{Generalized DIMM: GDIMM}

The Differential Image Motion Monitor ${ }^{17}$ (DIMM) is a well known and widely used instrument because of its simplicity. It is based on a small telescope with an entrance pupil made of 2 small sub-apertures ( $6 \mathrm{~cm}$ diameter) observing a bright single star with a short exposure time. The Generalized DIMM ${ }^{10}$ (GDIMM) is a DIMM updated by adding a third sub-aperture at the entrance pupil (see Fig. 2). This third sub-aperture $(10 \mathrm{~cm}$ diameter and $4 \mathrm{~cm}$ central obstruction) allows the instrument to deduce the isoplanatic angle and the wavefront coherence outer scale.

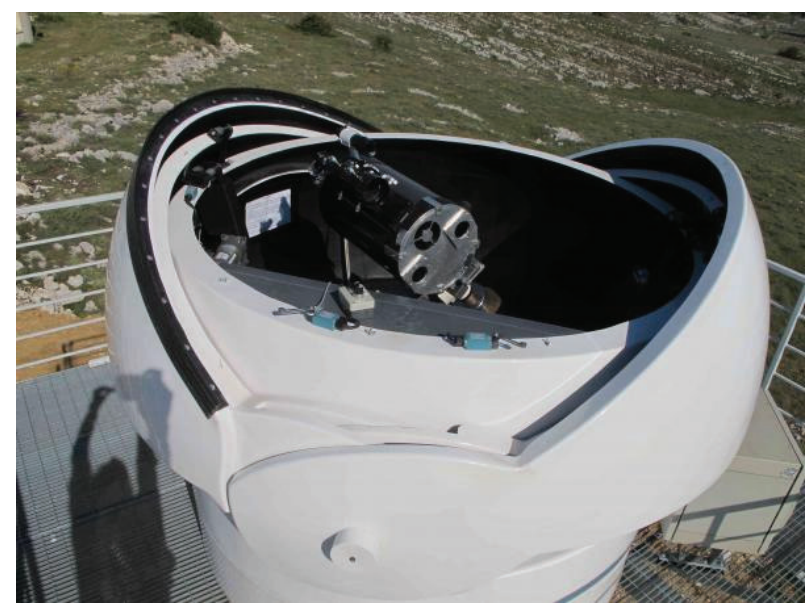

Figure 2. GDIMM instrument installed on the Calern Observatory.

The most important parameter measured by the GDIMM is the seeing, which is deduced from the Angle of Arrival (AA) fluctuations of the perturbed wavefront. These AA fluctuations are measured through the two $6 \mathrm{~cm}$ sub-apertures with the well known DIMM method.

Another important parameter for astronomy and free space optical links is the isoplanatic angle $\theta_{0}$ leading to the angular distance from which the incoming wavefront is uncorrelated. It is deduced from the scintillation of a single star measured through a $10 \mathrm{~cm}$ pupil with a $4 \mathrm{~cm}$ central obstruction. The principle of this $\theta_{0}$ estimation method is based on the similarity of the theoretical expressions of $\theta_{0}$ and the scintillation index $s .{ }^{18,19}$ However, Ref. 20 shown that the scintillation can be affected by the presence of the Moon in the nearby of the observed 
bright star. Therefore, in such conditions, the isoplanatic angle deduced form scintillation could be also affected by the Moon light.

The most difficult parameter to measure is the wavefront coherence outer scale $\mathcal{L}_{0}$. The GDIMM instrument uses the variances of AA fluctuations through different size sub-apertures by means of the von Karman model (see Ref. 3 for more details).

In the other hand, the coherence time $\tau_{0}$ relevant for adaptive optics and interferometry, is given by $\tau_{0}=$ $0.31 \frac{r_{0}}{\bar{v}}$, where $\bar{v}$ the effective wind speed, is a weighted average of the wind speed on the whole atmosphere. $r_{0}$ is the well known Frieds parameter. Ref. 21 has shown that it is possible to deduce the effective wind speed from the temporal structure functions of the AA fluctuations.

The GDIMM instrument is fully automatic and all parameters are measured and computed in real time and are uploaded on the CATS website* (see Fig. 3). This website is daily used by observers in Calern Observatory during the observations.

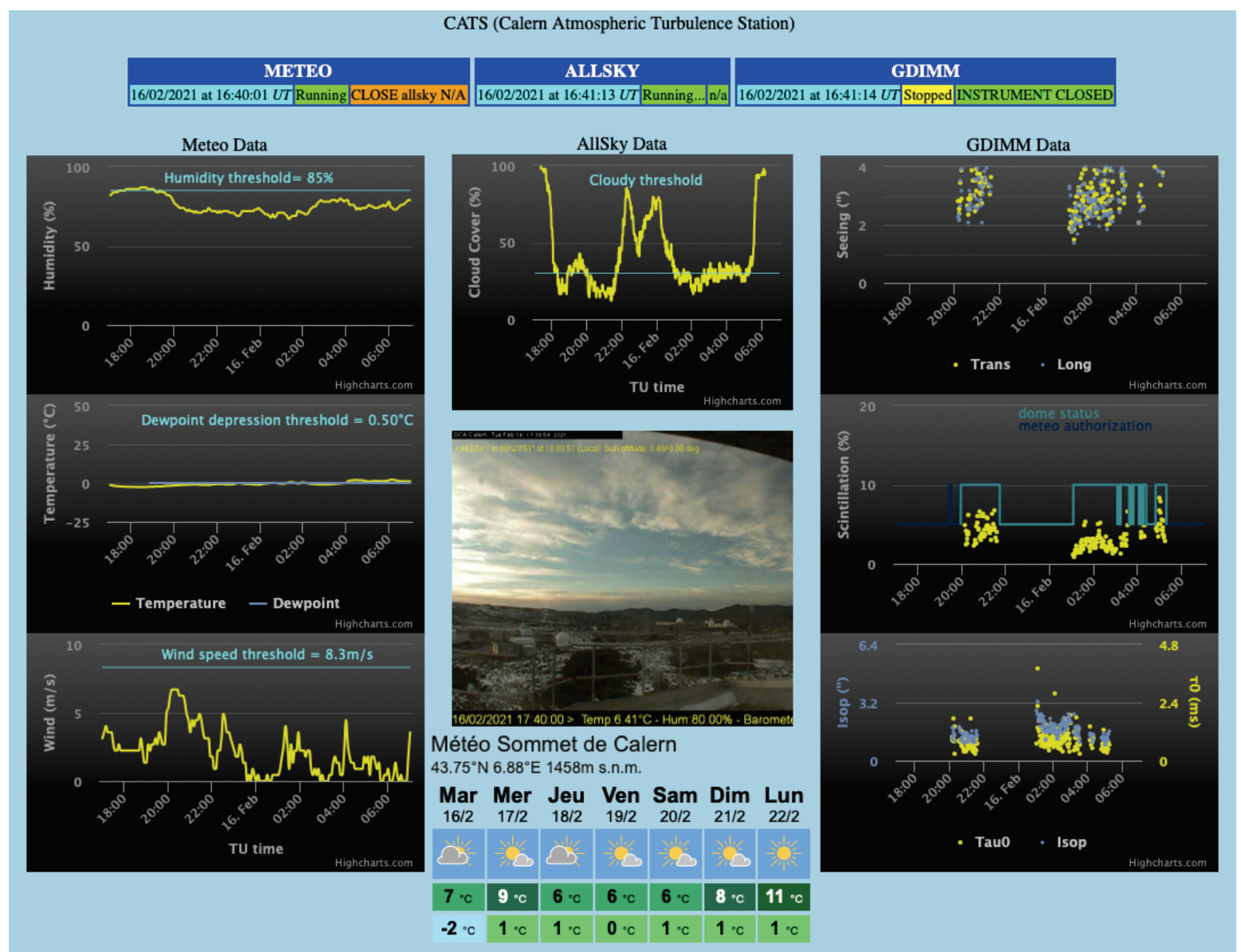

Figure 3. GDIMM results uploaded in real time on the CATS website.

\subsection{The Profiler of Moon Limb: PML}

The PML instrument is a profiler of the $C_{n}^{2}$ with the high vertical resolution. The $C_{n}^{2}$ is the structure constant of the refractive indexe fluctuations of the atmosphere. It gives information of the turbulence energy of each layer. The PML instrument is based on a differential method by observation of the lunar or solar limb through two sub-apertures (see Fig. 4). The Moon or Solar limb acts as a continuum of double stars with all possible

\footnotetext{
*https://cats.oca.eu
} 
angular separations required between two points to scan the atmosphere with a very fine resolution. Doing measurements on both Sun and Moon, the PML instrument gives also access to daytime measurements which are really important for free space optical links.
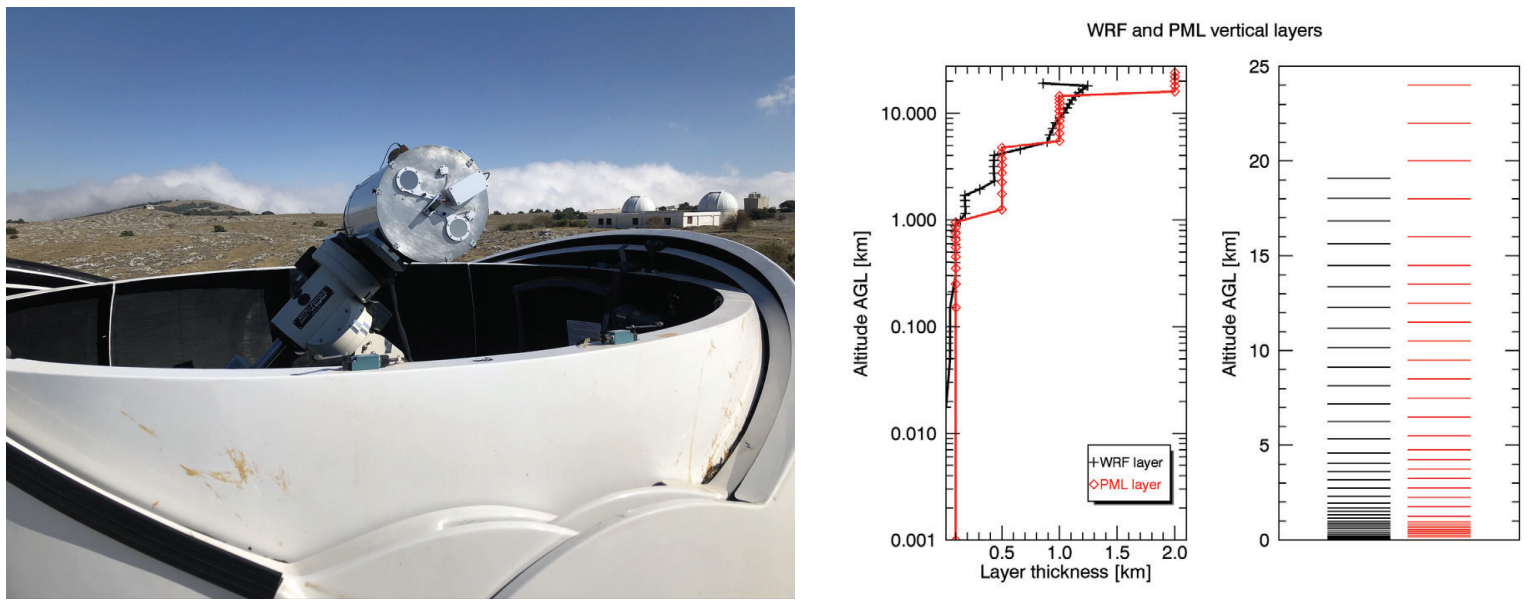

Figure 4. Left: PML instrument installed on the Calern Observatory. Right: Vertical resolution reached by the PML (red) and by the forecasting tool (black) (see section 2.3)

The vertical profile of the $C_{n}^{2}$ is deduced from the measurement of the angular correlation of the fluctuation differences in the wavefront AA deduced from the motion of the Moon (or Sun) limb image. The AA fluctuations are measured perpendicularly to the lunar (or solar) limb leading to transverse correlations for different angular separations along the Moon (or Sun). For more details about the computation method, see Refs. 3,14. Fig. 4, right, shows that the highest vertical resolution, $\Delta h=100 \mathrm{~m}$, is reached for the ground layer and it decreases progressively to $\Delta h=2000 \mathrm{~m}$ for the highest layers $(h>15 \mathrm{~km})$.

From this vertical profile, it is easy to compute integrated parameters such as the seeing or the isoplanatic angle. This later is also deduced from AA correlations along the Moon or Sum limb ${ }^{20}$ and it is not biased like the one deduced by the GDIMM with the presence of the Moon (see section 2.1).
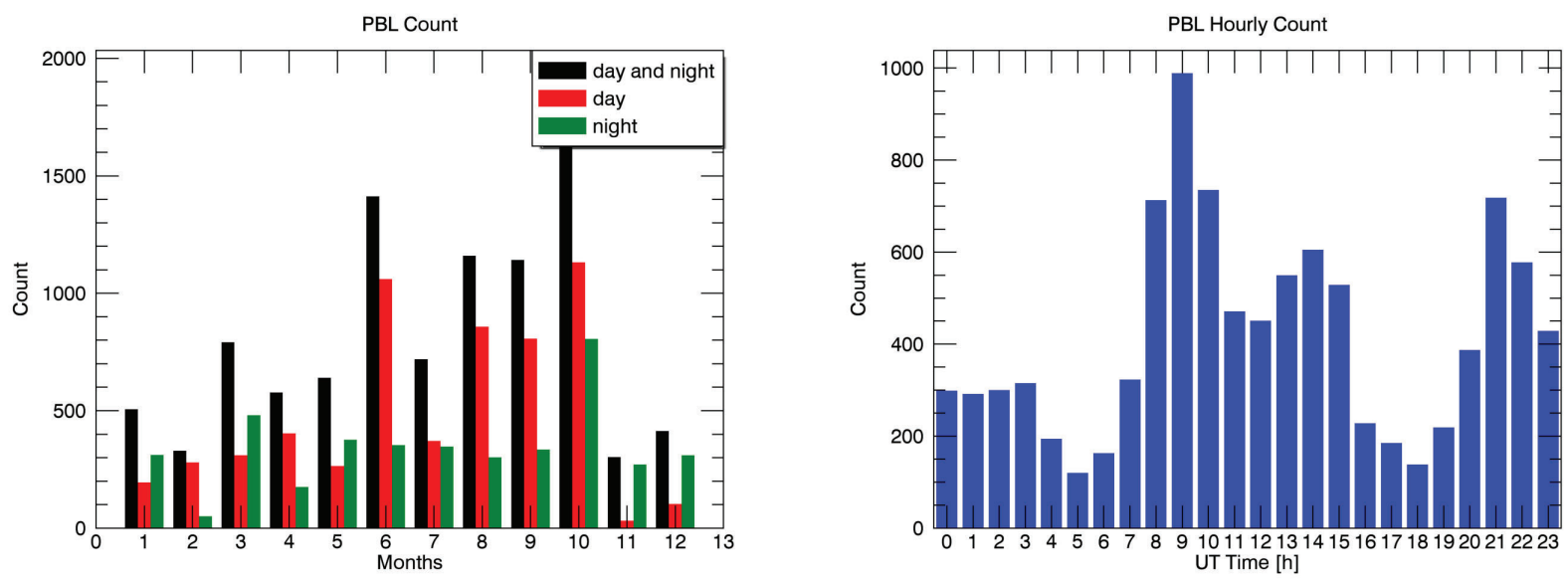

Figure 5. PML data distribution between 2015 and 2019. Left: monthly count. Right: Hourly count.

Since 2015, the PML instrument has acquired a large database which has been used within several astronomical and optical telecommunication projects. Figure 5 shows the PML data distribution computed monthly and 
hourly between 2015 and 2019. It appears that there are more measurements during the summer and during the day. This is mainly due to the fact that the Moon is not always visible.

\subsection{Calern forecasting}

The last tool we have developed for CATS station is the forecasting of atmospherical and turbulence conditions. We use the non-hydrostatic mesoscale model called Weather Research and Forecasting (WRF) developed in the National Center for Atmospheric Research (NCAR), USA. ${ }^{22}$ This model allow us to predict weather conditions within a tridimensional domain. From this weather forecasts we use an empirical model deduced from the analysis of balloon radio-sounding launched around the world. ${ }^{4-7,23}$ This model called BDTM (Balloon Derived Turbulence Model) follows equations hereafter:

$$
\begin{gathered}
C_{T}^{2}(h)=\phi(h) \chi(h) s(h)^{1 / 2} \\
\chi(h)=\frac{\delta \theta}{\delta h} \\
s(h)=\left(\frac{d U^{2}}{d h}+\frac{d V^{2}}{d h}\right)^{1 / 2}
\end{gathered}
$$

where the $C_{T}^{2}$ is the structure constant of temperature fluctuations, $\chi$ is the vertical gradient of the potential temperature $\theta, h$ is the altitude, $U$ and $V$ are the wind speed respectively in the direction West-East and SouthNorth, and $s$ is the horizontal wind shear. $\phi(h)$ is the vertical profile deduced empirically from the analysis of the balloons radio-sounding,

$$
\phi(h)=\frac{\left\langle C_{T}^{2}(h)\right\rangle_{m}}{\langle\chi(h)\rangle_{m}\langle s(h)\rangle_{m}^{1 / 2}}
$$

where \langle\rangle$_{m}$ is the median value.

Finally, from $C_{T}^{2}$ we can deduce the $C_{n}^{2}$ following the well-known Gladstone's formula and others integrated parameters (seeing, isoplanatic angle, coherence time).

$$
C_{n}^{2}(h)=\left(\frac{80.10^{-6} P(h)}{T(h)^{2}}\right)^{2} C_{T}^{2}(h)
$$

where $P(h)$ and $T(h)$ are respectively the vertical profiles of the atmospheric pressure and absolute temperature.

Since the end of July 2019, we have implemented a fully automatic prediction tool above the Calern Observatory using the aforementioned models. This prediction cover the next $48 \mathrm{~h}$ and upload the results on the CATS website (see Fig. 6).

In Ref. 7, we have used these predictions and the CATS database to constrain the empirical model by local measurements. This upgrade, called SL (Site Learning) method, brings a real improvement as shown in Fig. 7. Indeed, regarding these plots it appears that the predicted seeing is closer to the measured one and the dispersion is lower. This SL method is continuously improved thanks to the continuous expansion of the database.

The last ongoing implementation about the predictions concerns the possibility to use our large database in Machine Learning (ML) algorithms. This possibility offers the advantage to have short-terms predictions $(<2 \mathrm{~h})$ with a better accuracy that the one obtained from forecasting models. For more detailed about this tool currently in development, see Ref. 24.

In parallel, an ongoing study tries to retrieve the vertical profiles of the outer scale $L_{0}$ from measurements and predictions of weather conditions. This work could allow us to use also a theoretical model in complement of the empirical method presented here above. The preliminary results of this study are presented by A. Rafalimanana in another paper of this ICSO conference. 

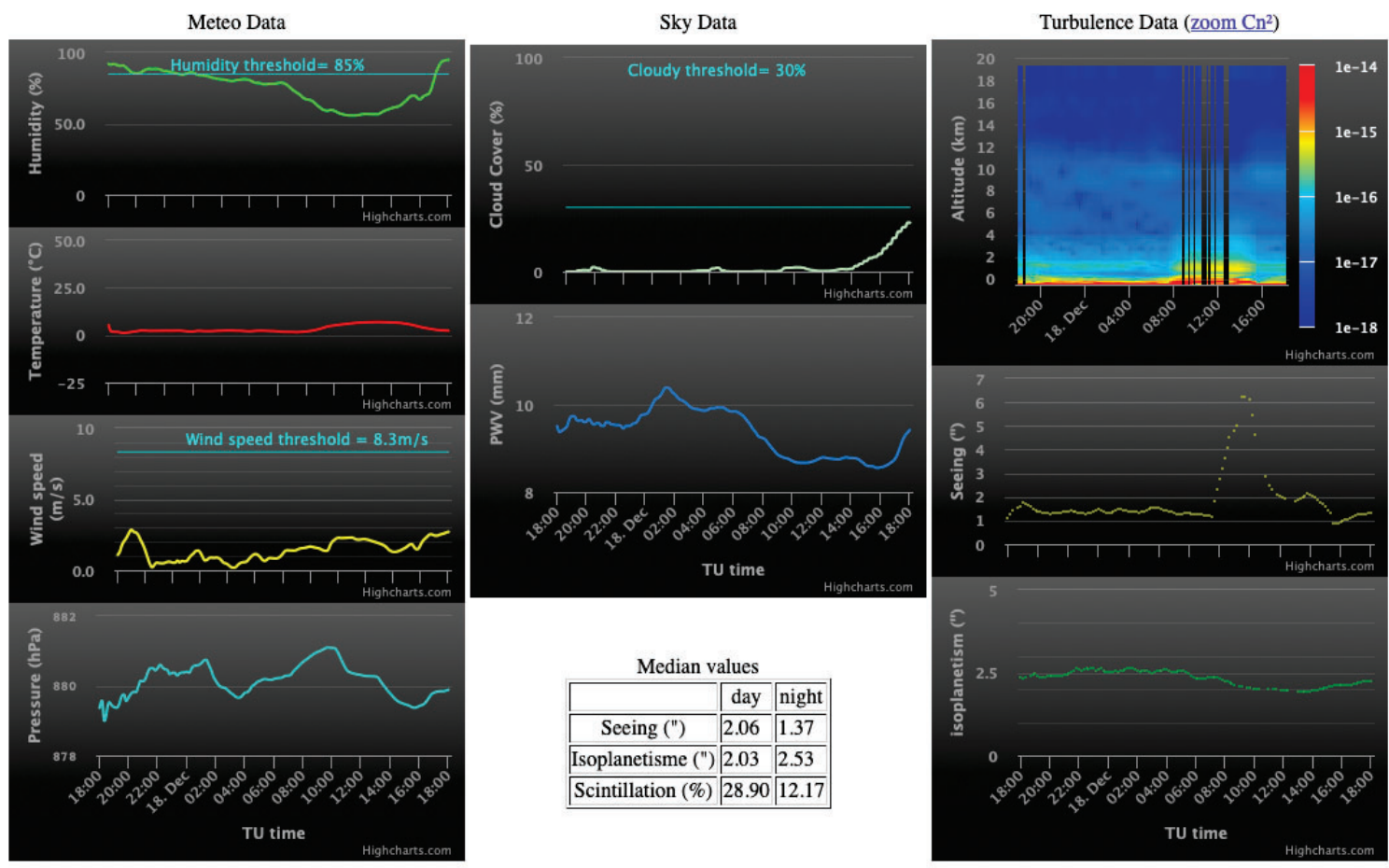

Figure 6. Calern Forecasting results available every day on the CATS website.
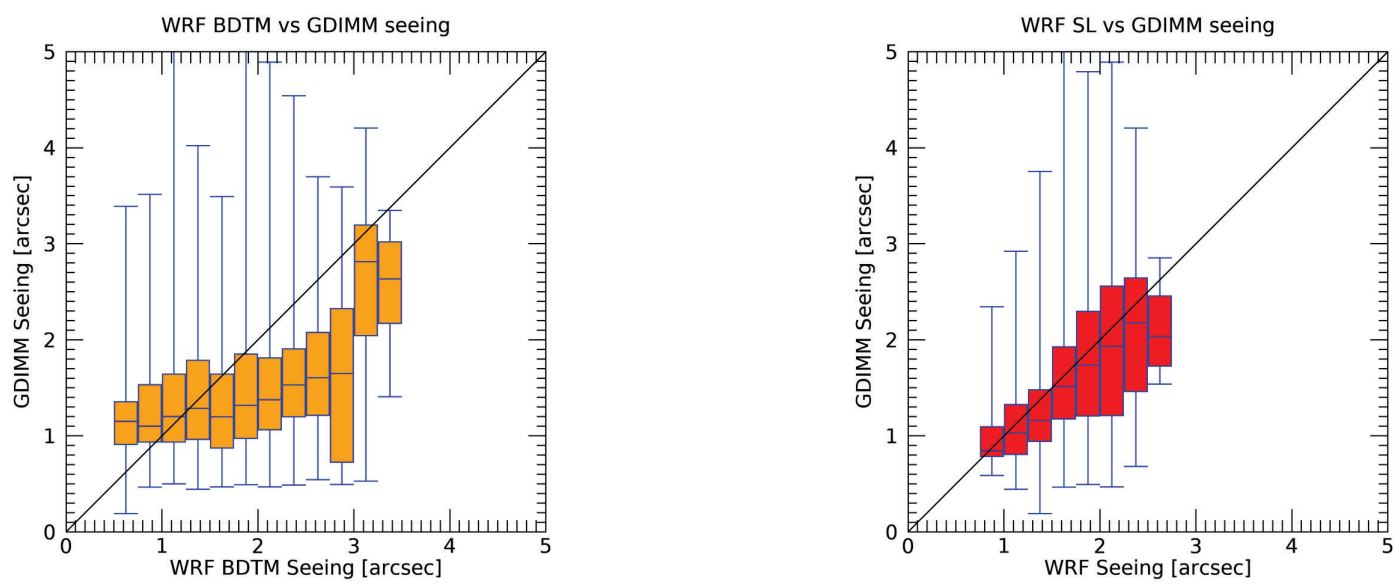

Figure 7. Scatter plot shown as box plot of the seeing forecasted using both BDTM (left) and SL (right) method and measured with GDIMM. The box corresponds to interval between first and third quartile. Within the box, the median values is plotted. The whiskers corresponds to extrema.

\section{DISCUSSION}

The CATS station is installed and operational at the Calern Observatory since autumn 2015. CATS is fully autonomous and monitors atmospheric turbulence parameters continuously thanks to a set of new generation instruments. In particular CATS is equipped with the PML which is a profiler of turbulence measuring the conditions from the first meters above the ground to the borders of the atmosphere with the highest resolution known and during daytime and nighttime. All these points are the reason why the CATS station is involved in many scientific and educational projects at the Calern Observatory such as: 
- study of turbulence impact on the laser links of the MéO Laser Ranging Station;

- development of Adaptive Optics projects;

- study of laser uplink propagation in the atmosphere thanks to the T2L2 space mission;

- campaign involving optical telecommunication from space to ground with the SOTA satellite and MéO laser ranging station.

- an ongoing European project with ESA uses the CATS station as a reference station in an optical telecommunication context.

Another campaign has been performed with the Optical PAyload for Lasercomm Science (OPALS) on International Space Station in spring 2016 and recently with the DLR OSIRIS instrument at the end of 2019. For these types of campaign, the PML instrument is very useful to understand the link budget of the lunar laser ranging activity at the $\mathrm{MéO}$ telescope. In addition, several other projects regarding adaptive optics systems are planned at the MéO telescope and C2PU telescope and they will benefit of the data given by the CATS station.

In addition, since more than 18 months, CATS is also equipped with a forecasting tool doing daily predictions of all atmospheric conditions (weather and turbulence) for the next 48h. These predictions have been tested and optimized thanks to a site learning method 7. In addition, a new tool using both the CATS database and the aforementioned $48 \mathrm{~h}$ predictions is in development. This later uses machine learning algorithm to compute a short-terms prediction in order to increase the accuracy of the mid-terms ones24. These predictions are of a real interest for observers at Calern because they give them an important information in advance to allow them to plan their observations. Moreover, such a prediction tool is important for free space optical link context because it will give information in advance on the availability of the ground station to receive signals from satellites.

Finally, the CATS station is used each year for on sky practical work for students of the Université Côte d'Azur (UCA).

\section{ACKNOWLEDGMENTS}

This CATS project has been done under the financial support of CNES, Observatoire de la Côte d'Azur (OCA), Labex First TF, AS-GRAM, Federation Doblin, Université de Nice-Sophia Antipolis and Region Provence Alpes Côte d'Azur. We would like to thank all the technical and administrative staff of the Observatoire de la Côte d'Azur, our mechanical engineer Christophe Bailet and our colleagues from the AstroGéo team from GéoAzur laboratory for their help and support all along the project namely Pierre Exertier, Etienne Samain, Dominique Albanèse, Mourad Aimar, Jean-Marie Torre, Emmanuel Tric, Thomas Lebourg and Sandrine Bertetic. We gratefully thank the NCEP/NCAR for the availability of the WRF tool and for providing the GFS meteorological data. We thank the SRTM for giving access to the high resolution topographic data. We would also like to thank the Mesocentre SIGAMM of the Observatoire de la Côte d'Azur for hosting our model and for their help in all the installation process.

\section{REFERENCES}

[1] Chabé, J., Ziad, A., Fantéï-Caujolle, Y., Aristidi, É., Renaud, C., Blary, F., and Marjani, M., [The Calern atmospheric turbulence station], vol. 9906 of Society of Photo-Optical Instrumentation Engineers (SPIE) Conference Series, $99064 \mathrm{Z}$ (2016).

[2] Ziad, A., Chabé, J., Fantei-Caujolle, Y., Aristidi, E., Renaud, C., and Ben Rahhal, M., "CATS: an autonomous station for atmospheric turbulence characterization," in [Proceedings of the SPIE], Society of Photo-Optical Instrumentation Engineers (SPIE) Conference Series 10703, 107036L (July 2018).

[3] Ziad, A., Chabé, J., Fantei-Caujolle, Y., Aristidi, E., Renaud, C., and Giordano, C., "The Calern Atmospheric Turbulence Station," in [Proceedings of the sixth AO4ELT Conference], (2019).

[4] Giordano, C., Vernin, J., Vázquez Ramió, H., Muñoz-Tuñó, C., Varela, A. M., and Trinquet, H., "Atmospheric and seeing forecast: WRF model validation with in situ measurements at ORM," Monthly Notices of the Royal Astronomical Society 430, 3102-3111 (Apr. 2013). 
[5] Giordano, C., Vernin, J., Trinquet, H., and Muñoz-Tuñón, C., "Weather Research and Forecasting prevision model as a tool to search for the best sites for astronomy: application to La Palma, Canary Islands," Monthly Notices of the Royal Astronomical Society 440, 1964-1970 (May 2014).

[6] Giordano, C., Prédiction et optimisation des techniques pour lâĂŹobservation aİ̆ haute rè̇Azsolution angulaire et pour la future génération de très grands télescopes, $\mathrm{PhD}$ thesis, Université de Nice Sophia Antipolis, Nice, France (2014).

[7] Giordano, C., Rafalimanana, A., Ziad, A., Aristidi, E.and Chabé, J., Fantéi-Caujolle, Y., Renaud, C., and Giordano, C., "Contribution of statistical site learning to improve optical turbulence forecasting," in press Monthly Notices of the Royal Astronomical Society (2020).

[8] Aristidi, E., Fanteї-Caujolle, Y., Ziad, A., Dimur, C., Chabé, J., and Roland, B., [A new generalized differential image motion monitor], vol. 9145 of Society of Photo-Optical Instrumentation Engineers (SPIE) Conference Series, 91453G (2014).

[9] Aristidi, E., Fantei-Caujolle, Y., Chabé, J., Renaud, C., Ziad, A., and Ben Rahhal, M., "Turbulence monitoring at the Plateau de Calern with the GDIMM instrument," in [Proceedings of the SPIE], Society of Photo-Optical Instrumentation Engineers (SPIE) Conference Series 10703, 107036U (July 2018).

[10] Aristidi, E., Ziad, A., Chabé, J., Fantéi-Caujolle, Y., Renaud, C., and Giordano, C., "A generalized differential image motion monitor," Monthly Notices of the Royal Astronomical Society 486, 915-925 (Jun 2019).

[11] Ziad, A., Blary, F., Borgnino, J., Fanteï-Caujolle, Y., Aristidi, E., Martin, F., Lantéri, H., Douet, R., Bondoux, E., and Mekarnia, D., "PML/PBL: A new generalized monitor of atmospheric turbulence profiles," in [Proceedings of the Third AO4ELT Conference], Esposito, S. and Fini, L., eds., 126 (Dec. 2013).

[12] Blary, F., Ziad, A., Borgnino, J., Fantéï-Caujolle, Y., Aristidi, E., and Lantéri, H., [Monitoring atmospheric turbulence profiles with high vertical resolution using PML/PBL instrument], vol. 9145 of Society of PhotoOptical Instrumentation Engineers (SPIE) Conference Series, 91453H (2014).

[13] Aristidi, E., Ziad, A., Fantéi-Caujolle, Y., Chabé, J., Giordano, C., Renaud, C., and Lantéri, H., "Monitoring daytime and nighttime optical turbulence profiles with the PML instrument," in [Proceedings of the sixth AO4ELT Conference], (2019).

[14] Chabé, J., Aristidi, E., Ziad, A., Lantéri, H., Fanteï-Caujolle, Y., Giordano, C., Borgnino, J., Marjani, M., and Renaud, C., "PML: a generalized monitor of atmospheric turbulence profile with high vertical resolution," Applied Optics 59, 7574 (Sept. 2020).

[15] Chabé, J., Blary, F., Ziad, A., Borgnino, J., Fanteï-Caujolle, Y., Liotard, A., and Falzon, F., "Optical turbulence in confined media: part I, the indoor turbulence sensor instrument," Applied Optics 55, 7068 (Sept. 2016).

[16] Blary, F., Chabé, J., Ziad, A., Borgnino, J., Fanteï-Caujolle, Y., Liotard, A., and Falzon, F., "Optical turbulence in confined media Part II:first results using the INTENSE instrument," Applied Optics 56, 6272 (July 2017).

[17] Sarazin, M. and Roddier, F., "The ESO differential image motion monitor," Astronomy and Astrophysics 227, 294-300 (Jan. 1990).

[18] Loos, G. C. and Hogge, C. B., "Turbulence of the upper atmosphere and isoplanatism," Applied Optics 18, 2654-2661 (Aug. 1979).

[19] Ziad, A., Conan, R., Tokovinin, A., Martin, F., and Borgnino, J., "From the Grating Scale Monitor to the Generalized Seeing Monitor," Applied Optics 39, 5415-5425 (Oct. 2000).

[20] Ziad, A., Aristidi, E., Chabé, J., and Borgnino, J., "On the isoplanatic patch size in high-angular resolution techniques," Monthly Notices of the Royal Astronomical Society 487, 3664-3671 (Aug. 2019).

[21] Ziad, A., Borgnino, J., Dali Ali, W., Berdja, A., Maire, J., and Martin, F., "Temporal characterization of atmospheric turbulence with the Generalized Seeing Monitor instrument," Journal of Optics 14, 045705 (Apr. 2012).

[22] Skamarock, W. C., Klemp, J. B., Dudhia, J., Gill, D., Liu, Z., Berner, J., Wang, W., Powers, J., Duda, M., Barker, D., and Huang, X.-Y., "A Description of the Advanced Research WRF Version 4," tech. rep., NCAR (2019). 
[23] Trinquet, H. and Vernin, J., "A statistical model to forecast the profile of the index structure constant $C_{N}^{2}$," Environmental Fluid Mechanics 7, 397 (Sept. 2007).

[24] Giordano, C., Rafalimanana, A., Ziad, A., Aristidi, E., Chabé, J., Fanteï-Caujolle, Y., and Renaud, C., "Statistical learning as a new approach for optical turbulence forecasting," in [Society of Photo-Optical Instrumentation Engineers (SPIE) Conference Series], Society of Photo-Optical Instrumentation Engineers (SPIE) Conference Series 11448, 114484E (Dec. 2020). 